
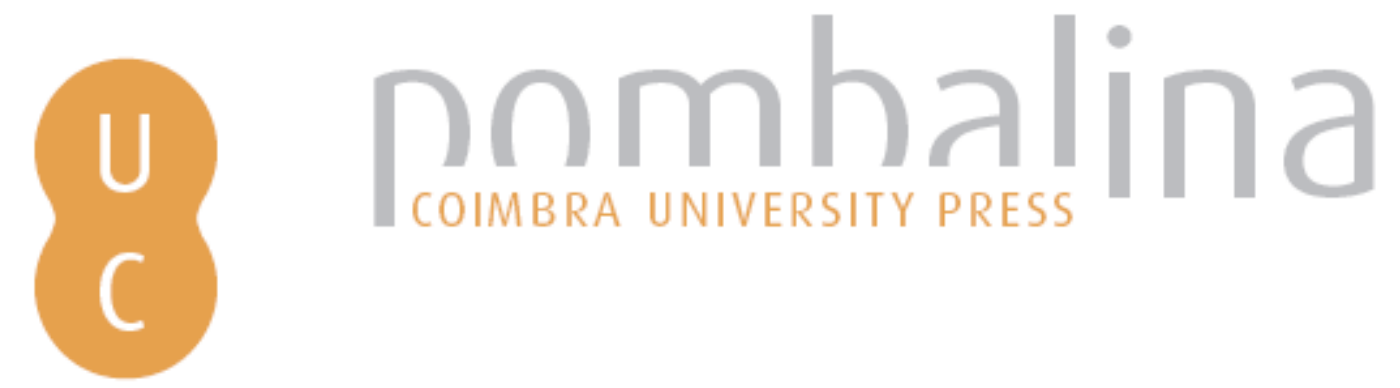

\title{
A casa da ilha e a casa do bairro municipal: dois módulos na construção de morfologias de padrão geométrico
}

Autor(es): $\quad$ Cardoso, Vasco

Publicado por: Imprensa da Universidade de Coimbra

URL

persistente: URI:http://hdl.handle.net/10316.2/30854

DOI: $\quad$ DOI:http://dx.doi.org/10.14195/978-989-26-0244-8_58

Accessed : $\quad$ 26-Apr-2023 16:13:41

A navegação consulta e descarregamento dos títulos inseridos nas Bibliotecas Digitais UC Digitalis, UC Pombalina e UC Impactum, pressupõem a aceitação plena e sem reservas dos Termos e Condições de Uso destas Bibliotecas Digitais, disponíveis em https://digitalis.uc.pt/pt-pt/termos.

Conforme exposto nos referidos Termos e Condições de Uso, o descarregamento de títulos de acesso restrito requer uma licença válida de autorização devendo o utilizador aceder ao(s) documento(s) a partir de um endereço de IP da instituição detentora da supramencionada licença.

Ao utilizador é apenas permitido o descarregamento para uso pessoal, pelo que o emprego do(s) título(s) descarregado(s) para outro fim, designadamente comercial, carece de autorização do respetivo autor ou editor da obra.

Na medida em que todas as obras da UC Digitalis se encontram protegidas pelo Código do Direito de Autor e Direitos Conexos e demais legislação aplicável, toda a cópia, parcial ou total, deste documento, nos casos em que é legalmente admitida, deverá conter ou fazer-se acompanhar por este aviso.

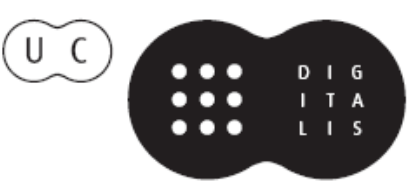




\section{TRUNFOS DE UMA}

\section{EOGRAFIA ACIVA}

\section{DESENVOLVIMENTO LOCAL,}

AMBIENTE,

ORDENAMENTO

E TECNOLOGIA

Norberto Santos

Lúcio Cunha

COORDENAÇÃO 
Vasco Cardoso

CEGOT e Curso de Doutoramento em Geografia do Departamento de Geografia da

Faculdade de Letras da Universidade do Porto

\section{A CASA DE ILHA E A CASA DO BAIRRO MUNICIPAL: DOIS MÓDULOSNA CONSTRUÇÃO DE MORFOLOGIAS DE PADRÃOGEOMÉTRICO}

\section{A INICIATIVA PRIVADA E A CRIAÇÃO DO MODELO ILHA}

A industrialização tardia e débil explica no país a falta de industriais e de tradiçóes associativas ou filantrópicas, capazes de produzir planos de intervenção na promoção de habitaçáo operária, reveladores de um padrão previamente definido (Matta 1909, pp. 99-142), em quantidade assinalável, como na Europa central. Só depois do Inquérito Industrial de 1881, entre 1883 e 1908 (Idem, pp. 170-173), o Estado tentou legislar, na influência de congéneres europeias (Ibidem, p. 144), visando os problemas de higiene e salubridade urbanas e do edificado. Para a Morfologia Urbana, dessas propostas destaca-se a opção pelo modelo de casa individual com jardins à frente e atrás, associadas aos pares ou em banda.

Num quadro de inoperância, as ilhas surgem como a soluçáo de compromisso entre os parcos rendimentos dos operários, as condiçóes oferecidas pelo território da cidade e as condiçóes económicas dos seus promotores burgueses de recursos limitados (Teixeira 1996, p. 76). O contexto específico do Porto imprimiu à soluçáo a sua originalidade. A eventual influência dos primeiros modelos de back-to-back houses, da industrializaçáo de Leeds, não se compatibiliza com o facto de os contactos com Inglaterra terem sido mantidos pela rica burguesia portuense desinteressada naquele tipo de investimento (Idem). Por outro lado, a influência do território geometricamente talhado pelo governo dos Almadas condicionou a modelação da morfologia ilhas ${ }^{1}$.

As ilhas foram implantadas no interior dos lotes esguios e compridos, com 25 palmos de largo, impostos pelo poder dos Almadas à frente da expansão urbana da cidade para norte, no final do século XVIII, por força das condicionantes físicas das traves de madeira suporte dos pisos. A força deste loteamento foi determinante na estruturaçáo da mancha construída desde então e, ainda hoje, é determinante na leitura da morfologia da cidade. O território das ilhas constituiu um primeiro arco, em torno do centro, onde se edificaram as casas da burguesia, em lotes adquiridos ou arrendados, na sequência da vitória do liberalismo, em 1832-34. Com a reforma do Código Civil de 1867, os donos dos terrenos deixaram de ter qualquer poder de decisão sobre o uso dos seus terrenos. Essa reforma deu lugar à desvalorização dos lotes, permitindo os sucessivos subemprazamentos e a instalação das ilhas, levando à deslocação da burguesia para novas áreas da cidade (Ibidem, pp. 155-156).

\footnotetext{
${ }^{1}$ Teixeira, 1996, p. 72: «A regularidade do loteamento urbano foi sem dúvida, de capital importância na emergência e consolidação da forma das ilhas.»
} 
A casa de ilha resultava da subtracção ao lote de um corredor de serventia, longitudinal com cerca de 1,5 metros de largura, e da divisáo do terreno sobrante em, geralmente, quadrados na base das casas. Em banda e encostadas ao muro do lateral do terreno, aquelas ficavam com uma única frente de aproximadamente 4 metros. A construção das casas era faseada à medida do aumento dos rendimentos dos promotores com o seu aluguer. Tendo havido procura garantida, foi questáo de tempo para a ilha se poder densificar no logradouro que lhe dava forma. Estas morfologias de deficiente construção, sem saneamento e sobreocupadas, impediam a ventilação cruzada e a iluminação solar.

Lendo a planta de Telles Ferreira, de 1892, é possível interpretar a presença de uma sobreposição de duas malhas urbanas, que traduzem a presença de duas cidades: a uma escala maior e à face da rua, a cidade burguesa; a uma escala mais fina, nos interiores dos quarteirôes daquela, a cidade composta por pequenos arruamentos de feição rural arrumados paralelamente ao lado uns dos outros. De facto, a estruturaçáo geométrica dos loteamentos almadinos evitou que para além do problema da salubridade, houvesse o problema do desligamento morfológico das ilhas do espaço urbano que ocuparam. Assim, a densificação do interior dos quarteiróes seguiu a estrutura geométrica preexistente o que permite uma leitura geral dos conjuntos como um padrão ortogonal obtido por sucessivas divisóes.

Graças à sua força económica e industrial e à sua posição estratégica no Norte, o Porto não só exportou bens, mas também modelos como as ilhas que apareceram um pouco por algumas localidades da regiáo (Fernandes 2005, p. 177). Por outro lado, o modelo é identificado por Teixeira (1994) como estando na origem dos cortiços no Rio de Janeiro. O modelo terá sido exportado para a cidade brasileira pelos portuenses lá emigrados, os principais moradores e proprietários dos cortiços. Por outro lado, ambas as morfologias surgem nos finais do século XIX, têm homóloga origem especulativa, têm igual desenho do lote urbano e idêntica localização no território das cidades.

\section{A Promoção Municipal E A IMPORTAÇÃo DE MODELOS}

Para o início da promoção pública de habitação foram decisivos a peste bubónica no Porto do final do século XIX e o Regulamento de Salubridade das Edificaçóes Urbanas $(\mathrm{RSEU})^{2}$, de 1903, que regrou a salubridade do espaço público e do edificado privado, abrangendo todas as construçóes, mesmo no interior dos quarteiróes. Nos artigos $13 .^{\circ}, 42 .^{\circ}$ e 43..$^{\circ}$ exigia: uma cubicagem de $25 \mathrm{~m}^{3}$ por pessoa, ventilaçáo directa e transversal, existência de latrina e pia de despejos exterior independentes e latrina contígua ou no interior do edifício e em compartimento ventilado. E, mantinha o legislado desde 1867 sobre a limitação dos pés-direitos a 3 metros de altura em qualquer piso (Fernandes 2005, p. 171).

No arranque das acçóes planeadas e projectadas, em 1899, a iniciativa conjunta de promoção de habitação para operários do jornal "O Comércio do Porto», da municipalidade e de alguns beneméritos, na reacçáo ao modelo insalubre seguiram o caminho da ruptura e optam por modelos de casas quádruplas, evocativos da casa unifamiliar - sinónimo coevo de habitação salubre (Moley 1991, p. 19). Havia dois modelos que se destacavam: o do arqui-

\footnotetext{
${ }^{2}$ Fernandes, 2005, p. 106, «... articulado é semelhante à lei francesa de 23 de Julho de $1884 \ldots$, citando de Nogueira, A. Rigaud, 1907, «A esthetica e a hygiene nas construçôes urbanas», A Construção Moderna, Ano VII.
} 
tecto Henry Roberts ${ }^{3}$ (1803-1876) e o do engenheiro Émile Müller (1823-1889) ${ }^{4}$. No primeiro caso sob um único tecto, juntavam-se quatro habitaçóes de modo a haver dois fogos por piso. As escadas de acesso ao piso eram abertas e incluídas no volume. As fachadas opostas facilitavam a ventilação interior, os agrupamentos em banda e a solução por pisos facilitava o agrupamento na vertical. O modelo esteve na origem das casas geminadas.

Ao contrário, o segundo autor distribuiu as habitaçóes, de dois pisos, em cada canto do quadrado da planta, ficando cada uma com duas frentes em ângulo recto. Apesar de muito divulgado na Europa ${ }^{5}$ o modelo esgotou-se. Como inconvenientes havia: mau arejamento interior, por não serem opostas as fachadas; condicionalismos no agrupamento em banda, pois todas as faces tinham vãos, e no agrupamento em altura, por causa da opção em dois pisos.

Chamado ao projecto no Porto, o arquitecto Marques da Silva adopta o modelo de Müller, que não seria por certo estranho à sua formação francesa (Cardoso 1997, pp. 8488). Do primeiro bairro em Monte Pedral até a última ampliação das futuras Colónias Operárias da Câmara Municipal do Porto, de 1917 a 1933, reviu-se o esgotamento do modelo de Müller. Embora incorporando com facilidade as normativas do RSEU, não resistiu aos condicionalismos da forma e, tendencialmente levou à sua aproximaçáo do modelo de Roberts, com a colaboração do D.L. - 4137, 25 Abril 1918. Esse estabeleceu, pela primeira vez em Portugal, o regime das casas unifamiliares para as classes menos abastadas, retomando a morfologia proposta no final da monarquia.

$\mathrm{Na}$ transição de modelos, interessa sublinhar que no território a opção foi por malhas de padráo ortogonal, dentro dos terrenos disponíveis, com expressão relevante na proposta de ampliação da Colónia Operária do Dr. Manuel Laranjeira ${ }^{6}$, onde se fizeram várias experiências no edificado.

\section{O PORTO, TERritório do Debate dos Modelos Públicos}

Face à estagnação na resolução do problema da habitação social, o Estado Novo implica-se como promotor nacional com o plano das casas económicas, de 1933, no aperfeiçoamento das leis de 1918 e 1928. Seguiu o conceito de cidade-jardim (Matos, 2001, p. 274) e, incluindo os bairros nos Planos Gerais de Urbanizaçáo ${ }^{7}$, criou novos territórios urbanos. Ao longo dos anos, o Estado Novo foi reconhecendo, em lei, que as casas económicas náo alojavam os mais carenciados (Batista 1999, p. 112).

\footnotetext{
${ }^{3}$ Colvin, 1995, pp. 820-821. «Roberts is best known as a pioneer of working-classes housing. (...) was one of the key figures in the history of rural and industrial housing.» A influência de Roberts, «laid the foundations for later experiments such as those at Port Sunlight, Bournville, and Letchworth Garden City», Curl, 2000, p. 646.

${ }^{4}$ Criou um módulo da verdadeira cidade fundacional ortogonal, edificada para os operários da Société Mulhousienne des Cités Ouvriers, em 1854. Inovadora em relação às outras Company Towns, por deixar de lado o paternalismo opressor do patrão/promotor.

${ }^{5}$ Foi estudada por Cerdá, em 1859, na «Teoría de la Contrucción de las ciudades», em Romón, 2003, pp. 7-9. Mas, Müller só viu o seu modelo aceite para Exposição Universal de Paris, de 1867, Garner, 1992, p. 44.

${ }^{6}$ AHCMP, Guia 19/ $2003-$ n. ${ }^{\circ} 88$.

${ }^{7}$ D.L. - 24802, de 21 de Dezembro de 1934. As Câmaras Municipais deviam promover a elaboração de Planos Gerais de Urbanizaçáo, mas a cartografia rigorosa base só começou a aparecer em 1941/42 (Fernandes, 2005, pp. 54-55).
} 
O Porto, além das experiências construídas até 1933, desenvolveu uma série de estudos e relatórios de onde se destaca o Inquérito Geral às ilhas, de 1939. No seguimento do inquérito, o município estabeleceu um plano segundo a estratégia defendida no relatório de Azeredo Antas e Manuel Monterroso, de $1934^{\circ}$. Apontava-se o local da prevista demoliçáo das ilhas para a implantação de blocos de habitação colectiva. Nomeadamente, demolir-seiam as ilhas próximas da ruína e, nas outras, demolir-se-ia uma casa em cada três, de modo a se poderem unir duas, criando novas casas com três frentes e o dobro da área. Os desalojados seriam, progressivamente realojados em blocos, dos quais o bloco Saldanha seria o modelo. Pela primeira vez, a estratégia passava pela intervenção na morfologia das ilhas, tornando-as salubres e com condiçóes de habitabilidade. Seria o modo de controlar o preço dos terrenos centrais e de não deslocar pessoas. O plano trazia a novidade de uma transformaçáo por continuidade, trabalhando as preexistências.

Para desenhar os blocos da Rua Duque de Saldanha, a Câmara do Porto voltou a chamar o arquitecto Marques da Silva. Trata-se de um edifício em U, no interior dos lotes, e um outro à face da rua, ambos com acessos por galeria aberta ${ }^{9}$ para o módulo-casa mínima, definido com o RSEU. Distante das convicçóes do Estado Novo a solução foi recusada (Teixeira 1992, pp. 82-83), em Agosto de 1939. Dependente dos fundos estatais, a Câmara retomou o modelo das casas geminadas, seguindo de perto a casa classe $A$ do programa das casas económicas e concebeu o "Bairro de Habitaçóes Populares de Rebordóes 1. a fase», em $1942^{10}$, na lógica da cidade-jardim: casas geminadas, a face da rua e com quintais atrás e ruas reproduzindo o perímetro do terreno.

\section{SOBREIRAS: ESQUISSO DA CIDADE MODERNA}

Depois da lei das casas desmontáveis, de 1938, aplicado no Porto com o D.L. - 33278, de 24 de Novembro de 1943, o Estado Novo português voltou a ceder na sua intransigência sobre modelos: com o D.L. - 34486 de 6 de Abril de 1945, introduziu o conceito das casas para pobres, em substituição das frágeis casas desmontáveis. Assim, o Porto pediu um subsídio extra para poder transformar as casas desmontáveis planeadas para a Corujeira ${ }^{11}$ em casas para pobres. O Porto tinha encontrado um enquadramento legal passível de resolver o problema das ilhas. Mas, a polémica dos modelos conheceria um último episódio, que remete para o bairro Presidente Carmona em Setúbal, a 20 de Fevereiro de $1950^{12}$, com o «ESTUDO COMPARATIVO DE DUAS SOLUÇÕES DE CASAS PARA POBRES (SOBREIRAS E SETÚBAL)», dos serviços da Câmara Municipal do Porto.

Num dos grandes quarteiróes que acabaram por ser as guias da expansão da cidade de Setúbal, desde o polémico Plano de Urbanização (Faria 1981, p. 141-144 e Lôbo 1995, pp. 175-176), de 10 de Março de 1945 até a década de 1970, construiu o município um bairro de casas para pobres. Apesar de o referido Plano náo abrir o tema da habitaçáo social

\footnotetext{
${ }^{8}$ Anteriormente já defendidas por Matta (1909, p. 237-253).

${ }^{9}$ Curl, 2000, pp. 645-646. Roberts tinha-a utilizado para, «elevando ruas» evitar o imposto vitoriano sobre os vão de janela.

${ }^{10}$ AHCMP, GUIA 5/2003 n.o 310, de Fevereiro de 1941.

${ }^{11}$ AHCMP, cota D-CMP/3/148. E para o Regado AHCMP, cota D-CMP/3/148.

${ }^{12}$ AHCMP, cota D-CMP/4 (102). Não foram encontradas outras referências.
} 
(Faria 1981, p. 143), Setúbal viu ainda construídos, até 1970, mais dois bairros, desta feita de iniciativa estatal ${ }^{13}$. Para o bairro municipal do Presidente Carmona, $1948^{14}$, houve uma primeira proposta de Jacobetty Rosa, recusada por ser próxima dos modelos dos bairros de casas económicas ${ }^{15}$. A 3 de Novembro de 1945, surge o arquitecto Raul Rodrigues Lima ${ }^{16}$ como encarregado do projecto ${ }^{17}$. Num território plano e destinado a pessoas com os mesmos parcos rendimentos, o padrão criado definiu uma malha ortogonal simétrica e tendencialmente homogénea, tal como em Rebordóes. A sua proposta utilizava casas geminadas e com volumetrias depuradas de decoração.

No Porto, o projecto de Sobreiras, do arquitecto municipal Luís de Almeida d'Eça, de Dezembro de $1949^{18}$, viu um pedido de reformulação a 30 de Março de $1950^{19}$. As casas geminadas projectadas, embora geradas pelo mesmo módulo-fogo das casas para pobres, apresentavam duas diferenças centrais e de ruptura, no âmbito da Morfologia Urbana, com o programa onde se inseriam: a cobertura era de uma água e muito pouco inclinada e o alçado numa linguagem racional e moderna, aproximavam mais a assemblagem de um pequeno paralelepípedo do que de uma casa unifamiliar; e o acesso aos fogos do primeiro piso era feito por uma escada completamente exterior ao volume, independente do acesso aos fogos do R/c, garantindo o piso de baixo exactamente igual ao de cima. O problema dos acessos estava directamente relacionado com o espaço urbano. As casas geminadas do programa das casas para pobres, faceavam o arruamento, ficando os quatro quintais para as traseiras. Assim, os habitantes do piso tinham de vir à rua para aceder ao seu quintal. Em Sobreiras, a solução de acessos em fachadas opostas estabelecia relação directa entre pisos e respectivos quintais, dispostos aos pares à frente de cada uma daquelas. As casas/paralelepípedos deixaram de facear a rua, sendo implantadas no meio de parcelas localizadas entre veredas e, quer em Sobreiras, quer na Corujeira, dado o acidentado do terreno, também em diferentes socalcos. Este cenário sem as regras compositivas, estruturadas em simetrias e ortogonalidades, próprias das intervençôes estatais da época, esquissava a descolagem dos blocos habitacionais do desenho das vias, na esteira da Carta de Atenas. A ruptura apresentada não poderá deixar de se relacionar com o I. ${ }^{\circ}$ Congresso Nacional dos Arquitectos, de 1948 e a defesa do Moderno.

$\mathrm{O}$ aditamento ao projecto de Sobreiras ${ }^{20}$, obteve aprovaçáo a 4 de Outubro, sem que se registassem as poucas alteraçóes consideradas pelo município, mas «dada a urgência da obra (...) [julgou-se] este estudo merecedor de aprovação superior ${ }^{21}$. Em 1953 o bairro ficou pronto e em 1954 arrancam os cinco blocos no terreno contíguo a Poente - o modelo base dos edifícios-tipo do Plano de Melhoramentos ${ }^{22}$, na influência francesa das

\footnotetext{
${ }^{13}$ Bairro de casas económicas de Nossa Senhora da Conceiçấo, ADS, Cota 0060, Livro de Actas 38, p. 130 vs. Bairro dos Pescadores (1945-1952), ADS, Cota 1163, n.o Processo 494.

${ }^{14}$ Câmara Municipal de Setúbal, 1948, p. 4.

${ }^{15}$ ADS, Cota 0060, Livro de Actas 39, p. 7 vs, de 21 de Setembro de 1945. ADS, Cota 1163, n. Processo 356, de 6 de Outubro de 1945. ADS, Cota 0060, Livro de Actas 39, p. 24 vs.

${ }^{16}$ Nunes 2003, p. 108 «o arquitecto Raul Rodrigues Lima foi aquele que melhor soube inventar e reproduzir a sensibilidade estética herdada de Duarte Pacheco".

${ }^{17}$ ADS, Cota 0060, Livro de Actas 39, pp. 25-27. ADS, Cota 1166, n. ${ }^{\circ}$ Processo 364.

${ }^{18}$ AHCMP, Guia 5 - 2003 - n. ${ }^{\circ}$ 30. p. 77. AGCMP, cota C/E 2388.

${ }^{19}$ AHCMP, Guia 5 - 2003 - n. ${ }^{\circ}$ 30. p. 90.

${ }^{20}$ AGCMP, cota D-CMP/5 (73-2),pp. 27-29. Datado de 14 de Agosto de 1950.

${ }^{21}$ AHCMP, cota Guia 5/2003, n. ${ }^{\circ} 30$, pp. 88 e 88 vs.

22 Conseguiu-se levantar três alusóes a Sobreiras, como origem dos bairros seguintes: S. João de Deus, em 1955 (AGCMP, cota DMESG - 537); Pio XII, em 1958, (AGCMP, cota DMESG - 2311); Estudo de hipótese
} 
Habitations à Loyer Modere (Matos 1994, pp. 685-686). Para os blocos de Sobreiras foi fundamental o trabalho pioneiro tido em dois blocos, no remate da malha preexistente na Corujeira ${ }^{23}$, projecto de $1950^{24}$, para dar segurança na opção do acesso aos fogos por galerias abertas. Neste quadro, a constituição de padróes ortogonais homogéneos, gerados pelo mesmo módulo-habitação mínima do RSEU, transferiu-se para os blocos.

Com a experiência de Sobreiras, repetida em S. João de Deus, a Câmara conseguiu demonstrar a economia da construçáo em blocos multifamiliares nos terrenos livres e contíguos a áreas já urbanizadas ${ }^{25}$.

\section{CONCLUSÓES}

As morfologias de habitação de origem privada não derivaram de um modelo predeterminado. Para a promoção pública foram experimentados e utilizados modelos e leis de influência estrangeira. Como referiu Pereira de Oliveira (2007, p. 372), os grupos de moradias populares são uma «organização do espaço urbano resultante no seu geometrismo do prévio planeamento». E, tendo as ilhas sido guiadas pelos loteamentos almadinos, é sublinhando esse constrangimento geométrico que, embora algo indirectamente, se relacionam o padrão-ilha e o padrão-bloco.

O que se descobriu no bairro do Presidente Carmona já existia no bairro de Rebordóes. Para além de condicionar verbas às escolhas de modelos, a Direcção Geral dos Serviços de Urbanização recomendava visitas a outros bairros e enviava sugestóes desenhadas ${ }^{26}$.

Sobreiras marcou o início da apropriaçáo da Carta de Atenas para a morfologia habitacional plurifamiliar no Porto, depois desenvolvida no Plano de 1956 a 1966. O Estado não consegui evitar a construção em blocos distribuídos pelo terreno, mas conseguiu, de certo modo, adaptar os princípios da Carta de Atenas aos seus interesses: na localização dos empreendimentos nas áreas de expansão da urbanização na cidade; na implantação dos bairros contiguamente aos anteriores bairros de casas económicas, garantindo uma distribuição, pretensamente, equilibrada das diferentes classes sociais de menores rendimentos pela cidade; e na inclusão de equipamentos sociais no seio de cada bairro.

\section{REFERÊNCIAS BIBLIOGRÁFICAS}

Baptista, Luís V. 1999, Cidade e Habitação Social, Celta, Oeiras.

Câmara Municipal de Setúbal 1948, Porque se construiu o "Bairro do Presidente Carmona» ?, Câmara Municipal de Setúbal, Setúbal.

Câmara Municipal de Setúbal 1973, Setúbal - Cidade do rio azul, Serviços Sociais do Pessoal da Câmara Municipal de Setúbal, Setúbal.

\footnotetext{
de acrescentar um piso às primeiras casas construídas na Corujeira, utilizando as tipologias de Sobreiras, em 1959 (AGCMP, cota DMESG 2828).

${ }^{23}$ Boletim Municipal da Câmara Municipal do Porto, No 743, p. 443.

${ }^{24}$ AGCMP, cota DMESG - 1938, pp. 29.

${ }^{25}$ Câmara Municipal do Porto, 1956, p. 13 e pp. 18-19.

${ }^{26}$ AGCMP, cota DMESG - 2231, pp. 15 - 16: proposta de ampliaçáo para Sul do bairro da Corujeira. AGCMP, cota DMESG - 259, pp. 82 - 83: sugestão de estudo do bairro dos Olivais em Lisboa, dois dias depois do Decreto de Lei que aprovou o Plano de Melhoramentos.
} 
Câmara Municipal do Porto 1956, Plano de Salubrização das "Ilhas» do Porto, Câmara Municipal do Porto, Porto.

Cardoso, António 1997, O Arquitecto José Marques da Silva e a arquitectura no Norte do País na primeira metade do séc. $X X$, FAUP, Porto.

Colvin, Howard Montagu 1995, A Biographical Dictionary of British Architects 1600-1840, Yale Univerity Press, New Haven.

Curl, James Stevens 2000, A Dictionary of Architecture and Landscape Architecture, Oxford University Press, Nova York.

Faria, Carlos Vieira 1981, Novo fenómeno urbano, aglomeração de Setúbal: ensaio de sociologia urbana, Assírio e Alvim, Lisboa.

Fernandes, Mário Gonçalves 2005, Urbanismo e Morfologia Urbana no Norte de Portugal: Viana do Castelo, Póvoa de Varzim, Guimarães, Vila Real, Chaves e Bragança entre 1852 e1926, FAUPpublicaçóes, Porto.

Garner, John S. 1992, "Noisiel-sur-Marne and the Ville Industrielle in France» in The Company town: architecture and society in the early industrial age, Oxford University Press, Nova York, pp. 43-74.

Lôbo, Margarida Souza, 1995, Planos de Urbanização - A Época de Duarte Pacheco, DGOTDU e FAUP, Porto.

Matta, José Caeiro da 1909, Habitaçôes Populares, Imprensa da Universidade, Coimbra.

Matos, Maria de Fátima Loureiro de 2001, A habitação no grande Porto : uma perspectiva geográfica da evolução do mercado e da qualidade habitacional desde finais do séc. XIX até ao final do milénio, volume I, Dissertaçáo para Doutoramento em Geografia Humana na Faculdade de Letras da Universidade do Porto, Universidade do Porto, Faculdade de Letras, Porto.

Moley, Christian 1991, L' immeuble en formation: genèse de l'habitat collectif et evators intermédiaires, Pierre Mardaga, Liège.

Nunes, António Manuel 2003, Espaços e imagens da justiça no Estado Novo : templos da justiça e arte judiciária, Minerva, Coimbra.

Pereira de Oliveira, José Manuel 2007, O Espaço Urbano do Porto: Condiçóes Naturais e Desenvolvimento, Edição Fac-similada da edição original de 1973 do Instituto de Alta Cultura, Ediçóes Afrontamento., Porto.

Romón, María C. 2003, Influencias Europeas sobre la "Ley de Casas Baratas" de 1911: El referente de la "Loi des Habitations à Bon Marché» de 1894, Cuadernos de investigación urbanística n. ${ }^{\circ}$ 36, Instituto Juan de Herrera, Madrid.

Teixeira, Manuel C. 1992, «As estratégias de habitação em Portugal, 1880-1940» in Análise Social, vol. XXVII (115), $1992\left(1 .^{\circ}\right)$, Instituto de Ciências Sociais da Universidade de Lisboa, Lisboa, pp. 65-89.

Teixeira, Manuel C. 1994, "A habitação popular no século xix - características morfológicas, a transmissão de modelos: as ilhas do Porto e os cortiços do Rio de Janeiro", in Análise Social, vol. XXIX (127), 1994 (3.), Instituto de Ciências Sociais da Universidade de Lisboa, Lisboa, pp. 555-579.

Teixeira, Manuel C. 1996, Habitação popular na cidade oitocentista: as ilhas do Porto, F.C.G., Lisboa.

Arquivo Distrital de Setúbal (ADS).

Arquivo Histórico da Câmara Municipal do Porto (AHCMP).

Arquivo Geral da Câmara Municipal do Porto (AGCMP). 